\title{
Comparison of Antifungal Azole Interactions with Adult Cytochrome P450 3A4 versus Neonatal Cytochrome P450 3A7
}

\author{
Malika P. Godamudunage, Anne M. Grech, and Emily E. Scott \\ Departments of Medicinal Chemistry (M.P.G., A.M.G., E.E.S.) and Pharmacology (E.E.S.), University of Michigan, \\ Ann Arbor, Michigan
}

Received April 16, 2018; accepted July 9, 2018

\section{ABSTRACT}

Adult drug metabolism is dominated by cytochrome P450 3A4 (CYP3A4), which is often inhibited by antifungal azole drugs, resulting in potential alterations in drug metabolism and adverse drug/drug interactions. In the fetal and neonatal stages of life, the $87 \%$ identical cytochrome P450 3A7 (CYP3A7) is expressed but not CYP3A4. Azole antifungals developed for adults are also used in neonates, assuming they interact similarly with both enzymes, but systematic information is lacking. Herein a method was developed for generating recombinant purified CYP3A7. Thirteen different azoles were then evaluated for binding and inhibition of purified human CYP3A4 versus CYP3A7. All imidazole-containing azoles bound both enzymes via coordination to the heme iron and inhibited both with $\mathrm{IC}_{50}$ values ranging from $180 \mathrm{nM}$ for clotrimazole to the millimolar range for imidazole itself. Across this wide range of potencies, CYP3A4 was consistently inhibited more strongly than CYP3A7, with clotrimazole being the least selective (1.5-fold) inhibitor and econazole the most selective (12-fold). Observations for 1,2,4triazole-containing azoles were more varied. Most bound to CYP3A4 via coordination to the heme iron, but several also demonstrated evidence of a distinct binding mode at low concentrations. However, only posaconazole inhibited CYP3A4. Of the triazoles, only posaconazole inhibited CYP3A7, again less potently than CYP3A4. Spectral evidence for binding was weak or nonexistent for all triazoles. Overall, although the details of binding interactions do vary, the same azole compounds inhibit both enzymes, albeit with weaker interactions with CYP3A7 compared with CYP3A4.

\section{Introduction}

Human cytochrome P450 enzymes are responsible for the biotransformation of drugs (Zanger and Schwab, 2013), with CYP3A4 being the major adult enzyme. CYP3A4 has substantial potential for adverse drug-drug interactions when multiple substrates or a substrate and an inhibitor are coadministered. In neonates and infants until 6-12 months postgestational age, the $87 \%$ identical enzyme CYP3A7 is expressed instead of CYP3A4 (Stevens et al., 2003; Leeder et al., 2005). Although it is frequently assumed that CYP3A4 and CYP3A7 function similarly, evidence suggests these isoforms oxidize drugs differently (Williams et al., 2002; Granfors et al., 2006). Similarly, differential inhibition may further complicate expected disposition of coadministered drugs. The combination of differential expression and activity of CYP3A enzymes can significantly alter drug deposition in developing infants compared with adults (Treluyer et al., 2003; Blake et al., 2005; Stevens, 2006). This can be particularly relevant for preterm infants in the neonatal intensive care unit, who are often subject to concurrent drug therapies.

While adult drug metabolism is extensively studied, it is not as well understood in neonates and infants due to lack of controlled primary clinical data in these latter populations. Dosing regimens for neonates

This work was supported by National Institutes of Health Grant [F37 GM076343] to E.E.S. The content of this publication is solely the responsibility of the authors and do not necessarily represent the official views of the $\mathrm{NIH}$. https://doi.org/10.1124/dmd.118.082032. often derive from data gathered in adults. Off-label use of medications is common. Up to $65 \%$ of medications used in neonatal intensive care units in the United States are not approved by the Food and Drug Administration for infant use (Kumar et al., 2008; Hsieh et al., 2014). Therefore, properly establishing risk profiles and efficacy of these medications in infants can be a challenge. Evaluating functional differences between adult and fetal CYP3A isoforms in vitro may assist in avoiding potentially hazardous drug-drug interactions in neonates.

It is well established that compounds containing an azole frequently interact with cytochrome P450 enzymes to inhibit drug oxidation (Wilkinson et al., 1974; Tang et al., 2000). The nitrogen lone pair in azoles can directly coordinate the heme iron in P450 enzymes to elicit inhibition. Thus azole-containing drugs can have large effects on metabolism of coadministered pharmaceuticals. Azoles such as fluconazole, voriconazole, ketoconazole, and posaconazole were developed as antifungal drugs for adults and are also extensively used in pediatric populations (Gupta et al., 2004; Canadian Paediatric Society, 2008; Lass-Florl, 2010). Fluconazole is the most commonly used antifungal agent in extremely low birth weight infants (Hsieh et al., 2014). It has been shown to be safe for infants in very controlled trials (Kaufman et al., 2014), but the potential for drug interactions is inadequately understood.

Structural information on CYP3A/azole complexes is limited. There are no structures of CYP3A7 and only one crystal structure of CYP3A4 bound to an azole antifungal (Ekroos and Sjogren, 2006). This CYP3A4 complex contains two ketoconazole molecules. One coordinates the heme iron via its azole nitrogen, while the other is farther from the heme 
and in an antiparallel arrangement. A few other human CYP/azole complexes are available, including CYP51A1 with ketoconazole and econazole (Strushkevich et al., 2010) and CYP46A1 with voriconazole, clotrimazole (Mast et al., 2010), and posaconazole (Mast et al., 2013). All these azoles demonstrate nitrogen coordination directly to iron. A different binding mode is evident in Mycobacterium tuberculosis CYP121 complexed with fluconazole (Seward et al., 2006). Although direct azole coordination to iron is observed, there is also a second arrangement in which fluconazole forms a hydrogen bond to a water molecule that is in turn coordinated to the heme iron. This water-bridged binding mode has only been observed in a few other bacterial P450 enzyme structures (Poulos and Howard, 1987; Ouellet et al., 2011; Fonvielle et al., 2013), but electronic paramagnetic resonance data suggest this binding mode may be more common in solution (Lockart et al., 2018). Thus, at least two different azole binding modes are documented, although both are inhibitory (Seward et al., 2006).

This study employed structurally diverse azole drugs to systematically evaluate the inhibition and binding to CYP3A4 and CYP3A7. In general, imidazole-containing azoles coordinated to the heme iron of both enzymes and demonstrated higher affinity and more potent inhibition of CYP3A4 than CYP3A7. In comparison, most triazoles bound more weakly to CYP3A4 and with little evidence of binding to CYP3A7, and only posaconazole inhibited either enzyme. Notably, triazoles fluconazole and letrozole gave evidence of two distinct concentration-dependent binding modes to CYP3A4 that may be consistent with simultaneous binding of more than one ligand molecule. Overall, however, this work suggests that triazole compounds would be less likely to cause adverse drug-drug interactions at both life stages but that some imidazole antifungals may be slightly less problematic in neonates than in adults.

\section{Materials and Methods}

Expression and Purification of CYP3A4. A codon-optimized CYP3A4 gene was designed and ordered using gene synthesis from (GenScript, Piscataway, NJ), and cloned into the pCWori+ plasmid. The CYP3A4 gene was designed to result in truncation of amino acids 3-23 forming the N-terminal transmembrane helix and the addition of nucleotides encoding a C-terminal $\mathrm{His}_{4} \mathrm{tag}$, based on a previously reported CYP3A4 expression construct (Yano et al., 2004).

The resulting CYP3A4 protein was expressed and purified by adapting a previously reported protocol (Bart and Scott, 2017). The above pCW3A4 $423 \mathrm{H}$ construct was transformed into Escherichia coli DH5 $\alpha$ cells already containing the pGro7 plasmid (Takara Bio, Mountain View, CA) for expressing GroEL/ES chaperones and grown for $\sim 16$ hours at $37^{\circ} \mathrm{C}$ on a Lysogeny Broth (LB) plate. A single colony was then grown in $5 \mathrm{ml}$ of LB media for 6 to 7 hours at $37^{\circ} \mathrm{C}$ while shaking at $250 \mathrm{rpm}$ and subsequently used to inoculate $200 \mathrm{ml}$ of LB media which was then grown for $\sim 16$ hours at $28^{\circ} \mathrm{C}$ with shaking. Expression was performed using $500 \mathrm{ml}$ of Terrific Broth in 11 Erlenmeyer flasks. Each flask was inoculated with $10 \mathrm{ml}$ of the $200 \mathrm{ml}$ starter culture and grown at $37^{\circ} \mathrm{C}$ with shaking $(250 \mathrm{rpm})$ until the optical density at $600 \mathrm{~nm}\left(\right.$ O.D. $\left.{ }_{600}\right)$ reached 0.5 . At this point, the heme precursor $\delta$-aminolevulinic acid $(1 \mathrm{mM})$ and the chaperone inducer L-arabinose ( $4 \mathrm{mg} / \mathrm{ml}$ ) were added to the culture. The temperature was reduced to $28^{\circ} \mathrm{C}$, and cells were grown to an O.D. 600 of 0.6-0.8 prior to addition of isopropyl B-D-1thiogalactopyranoside $(1 \mathrm{mM})$ to initiate CYP3A4 expression. Cells were subsequently grown for 48 hours at $28^{\circ} \mathrm{C}$ with shaking $(190 \mathrm{rpm})$ before harvesting and freezing the cell pellet at $-80^{\circ} \mathrm{C}$ until use. All cultures above were supplemented with $100 \mu \mathrm{g} / \mathrm{ml}$ carbenicillin to select for the CYP3A4 plasmid and $20 \mu \mathrm{g} / \mathrm{ml}$ chloramphenicol to select for the chaperone plasmid.

To initiate purification, the frozen cell pellet was thawed and resuspended in lysis buffer $(500 \mathrm{mM}$ potassium phosphate, $500 \mathrm{mM} \mathrm{NaCl}$, and $20 \%$ glycerol, $\mathrm{pH}$ 7.4) in a volume equal to $10 \%$ of culture volume and supplemented with $1 \mathrm{mM}$ phenylmethylsulfonyl fluoride, followed by digestion with $0.3 \mathrm{mg} / \mathrm{ml}$ lysozyme for 30 minutes and sonication five times for 30 seconds each at $100 \%$ power. The cell lysate was then clarified by centrifugation at $7500 \mathrm{rpm}$ for 15 minutes. CYP3A4 was extracted by incubating the supernatant with $14 \mathrm{mM}$ 3-((3-cholamidopropyl) dimethylammonio)-1-propanesulfonate (CHAPS) for 1 hour. Ultracentrifugation at $120,000 \mathrm{~g}$ for 45 minutes was used to pellet lipids and the CYP3A4-containing supernatant was loaded onto a $30 \mathrm{ml} \mathrm{Ni-NTA}$ (Qiagen, Germantown, MD) column pre-equilibrated with loading buffer (100 mM potassium phosphate, $500 \mathrm{mM} \mathrm{NaCl}, 20 \%$ glycerol, $14 \mathrm{mM}$ CHAPS, $\mathrm{pH}$ 7.4). The column was washed with four column volumes (CV) of loading buffer followed by four $\mathrm{CV}$ of wash buffer (loading buffer supplemented with $4 \mathrm{mM}$ histidine) and eluted with three $\mathrm{CV}$ of elution buffer (10 $\mathrm{mM}$ potassium phosphate, $100 \mathrm{mM} \mathrm{NaCl}, 20 \%$ glycerol, $14 \mathrm{mM}$ CHAPS, $80 \mathrm{mM}$ histidine, $\mathrm{pH}$ 7.4). Eluted fractions with $A_{417} / A_{280}>1.0$ were pooled and diluted fivefold with carboxymethyl (CM) buffer ( $5 \mathrm{mM}$ potassium phosphate, $20 \%$ glycerol, $1 \mathrm{mM}$ EDTA, pH 7.4) containing $4 \mathrm{mM}$ CHAPS prior to loading on to a $5 \mathrm{ml} \mathrm{CM}$ sepharose column (GE Healthcare, Pittsburgh, PA). The column was washed with $10 \mathrm{CV}$ of the same buffer without detergent and eluted with CM elution buffer (50 mM potassium phosphate, 20\% glycerol, $1 \mathrm{mM}$ EDTA, $250 \mathrm{mM} \mathrm{NaCl}, \mathrm{pH}$ 7.4). Eluted fractions with $A_{417} / A_{280}>1.0$ were concentrated using Amicon Ultra centrifugal filters (Millipore, Billerica, MA) to $2 \mathrm{ml}$ and loaded on a Superdex 200 16/60 pg size exclusion column (GE Healthcare) run with the same buffer. All purification steps were accomplished at $4^{\circ} \mathrm{C}$. Purity of the final CYP3A4 was evaluated with sodium dodecyl sulfate polyacrylamide gel electrophoresis and UV-visible spectroscopy. P450 enzymes were quantified using an extinction coefficient of $0.091 \mathrm{mM}^{-1} \cdot \mathrm{cm}^{-1}$ (Omura and Sato, 1962). Aliquots were stored at $-80^{\circ} \mathrm{C}$ until further use.

Expression and Purification of CYP3A7. A synthetic, codon-optimized CYP3A7 gene was designed and ordered from GenScript based on the CYP3A4 construct above. Specifically, the gene has a truncation corresponding to amino acids 4-24 to omit the N-terminal transmembrane helix and addition of nucleotides coding for a C-terminal His 4 tag. This modified CYP3A7 gene was cloned into pCWori+ vector using the NdeI and HindIII restriction sites. Expression was performed as described above for CYP3A4.

To initiate purification, the cell pellet was resuspended in $20 \mathrm{mM}$ Tris, $20 \%$ glycerol, $\mathrm{pH} 8.0$ buffer (10\% of total culture volume) supplemented with $1 \mathrm{mM}$ phenylmethylsulfonyl fluoride and $10 \mathrm{mM} \beta$-mercaptoethanol prior to lysozyme addition and sonication as described for CYP3A4. The CYP3A7-containing membranes were first isolated by centrifugation at $120,000 \mathrm{~g}$ for 45 minutes. The membrane pellet was resuspended in $50 \mathrm{mM}$ Tris, $100 \mathrm{mM} \mathrm{NaCl}, 20 \%$ glycerol, $20 \mathrm{mM} \mathrm{MgCl}_{2}, 6 \mathrm{mM}$ ATP, $\mathrm{pH} 8.0$ buffer using a Dounce homogenizer prior to CYP3A7 extraction by adding $14 \mathrm{mM}$ CHAPS. Solubilized CYP3A7 was then separated from lipids by a second centrifugation at $120,000 \mathrm{~g}$ for 45 minutes, and the supernatant was loaded on a $30 \mathrm{ml}$ Ni-NTA column pre-equilibrated with loading buffer ( $50 \mathrm{mM}$ Tris, $500 \mathrm{mM} \mathrm{NaCl}, 20 \%$ glycerol, $20 \mathrm{mM} \mathrm{MgCl} 2,6 \mathrm{mM}$ ATP, 14 mM CHAPS, pH 8.0). This column was washed with $4 \mathrm{CV}$ of loading buffer, $4 \mathrm{CV}$ of wash buffer (50 mM Tris, $500 \mathrm{mM} \mathrm{NaCl}, 20 \%$ glycerol, $14 \mathrm{mM}$ CHAPS, $5 \mathrm{mM}$ histidine, $\mathrm{pH} 8.0$ ), and $2 \mathrm{CV}$ of potassium phosphate wash buffer (100 $\mathrm{mM}$ potassium phosphate, $500 \mathrm{mM} \mathrm{NaCl}, 20 \%$ glycerol, $14 \mathrm{mM}$ CHAPS, $\mathrm{pH}$ 7.4) and eluted with $3 \mathrm{CV}$ of elution buffer $(10 \mathrm{mM}$ potassium phosphate, $100 \mathrm{mM} \mathrm{NaCl}, 20 \%$ glycerol, $14 \mathrm{mM}$ CHAPS, $100 \mathrm{mM}$ histidine, $\mathrm{pH}$ 7.4). Eluted fractions with $\mathrm{A}_{417} / \mathrm{A}_{280}>1.0$ were pooled and further purified by $\mathrm{CM}$ sepharose and size exclusion chromatography as described for CYP3A4 above, except that the CM elution buffer for CYP3A7 contained $500 \mathrm{mM} \mathrm{NaCl}$ and the gel filtration buffer contained $100 \mathrm{mM} \mathrm{NaCl}$.

Expression and Purification of Cytochrome P450 Reductase and Cytochrome $\mathbf{b}_{5}$. Expression and purification of full-length rat NADPHcytochrome P450 reductase (Shen et al., 1989) and full-length human cytochrome $b_{5}$ (Bart and Scott, 2017) were accomplished as previously published.

Spectral Binding Assays. Ligand binding to CYP3A enzymes was evaluated by observing changes in the visible spectra in difference mode as described previously (DeVore et al., 2009). All ligand stocks were prepared in DMSO, except for imidazole, which could be dissolved in water. CYP3A enzymes at $1 \mu \mathrm{M}$ concentration were used in 1-cm-path length cuvettes to determine binding constants of ligands with moderate affinity, whereas $100 \mathrm{nM}$ protein in 5-cm-path length cuvettes were used for tighter binding ligands. In both cases, the change in absorbance after each addition of inhibitor $(\Delta \mathrm{A})$ was plotted versus the inhibitor concentration (S). GraphPad Prism (San Diego, CA) was used to determine the $K_{\mathrm{d}}$ and $\Delta \mathrm{A}_{\max }$ with nonlinear least-squares regression fitting to either the simple single-site binding equation (eq. 1) for compounds with moderate affinity or the Morrison equation (eq. 2), also known as the tight-binding equation, for those with high affinity. 


$$
\begin{gathered}
\Delta \mathrm{A}=\Delta \mathrm{A}_{\max } * S /\left(K_{d}+S\right) \\
\Delta \mathrm{A}=\Delta \mathrm{A}_{\max } \frac{\left(E+S+K_{d}\right)-\sqrt{\left(E+S+K_{d}\right)^{2}-4 E S}}{2 E}
\end{gathered}
$$

$E$ is protein concentration and $S$ is ligand concentration.

CYP3A Catalytic Assays and IC $_{50}$ Determination. Purified CYP3A (10 pmol), NADPH-cytochrome $\mathrm{P} 450$ reductase $(40 \mathrm{pmol})$, and cytochrome $b_{5}$ (10 pmol) were combined in $100 \mathrm{mM}$ potassium phosphate, $\mathrm{pH}$ 7.4. Luciferin isopropyl alcohol substrate ( $3 \mathrm{mM}$; Promega, Madison, WI) and inhibitor were added if applicable. To determine $K_{\mathrm{m}}$ values, a substrate concentration range of 0-65 $\mu \mathrm{M}$ was used. To determine $\mathrm{IC}_{50}$ values, substrate was constant at this $K_{\mathrm{m}}$ value. For inhibitors, a concentration range of $0-60 \mathrm{mM}$ was employed, with 13 concentrations spanning the appropriate range for each inhibitor. With the exception of imidazole, inhibitor stocks were in DMSO. The final DMSO concentration in each well was $<0.3 \%(\mathrm{v} / \mathrm{v})$ and $<1 \%(\mathrm{v} / \mathrm{v})$ for CYP3A4 and CYP3A7, respectively, as this resulted in $<25 \%$ inhibition in preliminary experiments. The reaction mixture $(25 \mu \mathrm{l})$ was dispensed into each well of white, flat-bottom 96-well plates (Corning Inc., Bedford, MA) The subsequent steps were automated using the GloMax Discover plate reader (Promega). The plate was preincubated at $37^{\circ} \mathrm{C}$ for 3 minutes, and reactions were initiated by adding $25 \mu \mathrm{lof}$ $200 \mu \mathrm{M}$ NADPH solution using injector 1 for a total volume of $50 \mu \mathrm{l}$. Each reaction well was incubated at $37^{\circ} \mathrm{C}$ for 30 minutes, after which $50 \mu \mathrm{l}$ of luciferin detection reagent with esterase was added using injector 2 to terminate the reaction and convert product to the luminescent form. The contents in wells were mixed by shaking the plate at $300 \mathrm{rpm}$ for 2 seconds after each addition above. The plate was incubated at the same temperature for an additional 20 minutes to stabilize the signal prior to reading luminescence. The D-luciferin product formed was quantitated using authentic D-luciferin standards treated in the same way as the samples. Reactions at each substrate and inhibitor concentration were performed in triplicate. Data were fit to the Michaelis-Menten equation to determine the $K_{\mathrm{m}}$ values for each enzyme or the dose response inhibitor (four parameter) equation to determine $\mathrm{IC}_{50}$ values \pm S.E. and $P$ values using GraphPad Prism.

\section{Results}

Recombinant Expression and Purification of Human Fetal CYP3A7. A codon-optimized version of the human CYP3A7 gene was engineered to encode for the wild-type human CYP3A7 protein, omitting the $\mathrm{N}$-terminal transmembrane helix and with a four-histidine tag appended to the $\mathrm{C}$ terminus, as has generally been done for many human proteins, including CYP3A4 (Yano et al., 2004) and CYP3A5 (Hsu et al., 2018). The resulting CYP3A7 protein was expressed in E. coli at high levels and was readily purified using membrane solubilization followed by sequential metal affinity, ion exchange, and size exclusion chromatography. The resulting CYP3A7 protein was obtained with high yield (average $215 \mathrm{nmol} / \mathrm{l}$ culture after three purification columns) and at high purity (average $\mathrm{A}_{417} / \mathrm{A}_{280}$ 1.6). Purified protein had a UV/Vis spectrum with a
Soret peak absorbance maximum at $417 \mathrm{~nm}$, consistent with water coordination to the heme iron (Fig. 1A). While addition of the substrates DHEAS and luciferin isopropyl alcohol did not obviously shift the Soret peak to lower wavelengths, as would be expected from their binding in the active site in such a way to displace the water (termed a type I spin state shift), the enzyme was catalytically active (vide infra). Thus, substrates may not initially bind closely enough to the heme iron to displace the water found on the heme in the resting state. In contrast, addition of imidazolecontaining compounds readily shifted the Soret peak to higher wavelengths (Fig. 1A), consistent with compound binding in the active site with nitrogen coordinating to the heme iron (termed a type II spin state shift), and resulted in enzyme inhibition (vide infra). The reduced-carbon monoxide difference spectrum was characterized by a peak at 449$449.5 \mathrm{~nm}$ typical of active enzyme, with little hint of a peak at $420 \mathrm{~nm}$ sometimes associated with the presence of inactive protein (Fig. 1B).

Selection of Azoles Evaluated with CYP3A Enzymes. Since the nitrogen of azoles can bind to the heme iron either directly or indirectly to inhibit P450 catalysis (vide supra), a structurally diverse set of azolecontaining drugs were evaluated (Table 1). Most of these drugs are clinically employed as antifungals: fluconazole, fosfluconazole, clotrimazole, ketoconazole, terconazole, oxiconazole, tioconazole, miconazole, posaconazole, and econazole. However, imidazole and two other azole drugs were included to explore further the structure/function relationship between azoles and CYP3A enzymes. Liarozole is a retinoic acid metabolizing (CYP26) blocking agent used for a skin condition called lamellar ichthyosis (Lucker et al., 1997; Vahlquist et al., 2014). Letrozole is an aromatase (CYP19A1) inhibitor used in breast cancer treatment (Regan et al., 2011). Overall, these azole drugs fall in to two general categories: those containing an imidazole (clotrimazole, liarozole, ketoconazole, oxiconazole, tioconazole, miconazole, and econazole) and those containing a triazole (fluconazole, fosfluconazole, letrozole, terconazole, and posaconazole). Their molecular weights range from 285 to $700 \mathrm{Da}$. Imidazole itself was also included as a very low molecular weight (68 Da) moiety that is not a drug. As such, the series not only probes interactions of drugs with clinically significant P450 enzymes in neonates versus adults but also serves as a means to compare the size and plasticity of the CYP3A active sites. While CYP3A4 is known to have a large (Yano et al., 2004) and flexible (Sevrioukova and Poulos, 2017) active site to accommodate diverse ligands, much less is known about these aspects of CYP3A7.

Azole Inhibition of CYP3A4 and CYP3A7. In this study the initial evaluation of CYP3A/azole interactions was undertaken by quantitating their respective abilities to inhibit CYP3A4- and CYP3A7-mediated metabolism of a common substrate. Preliminary studies with recombinantly
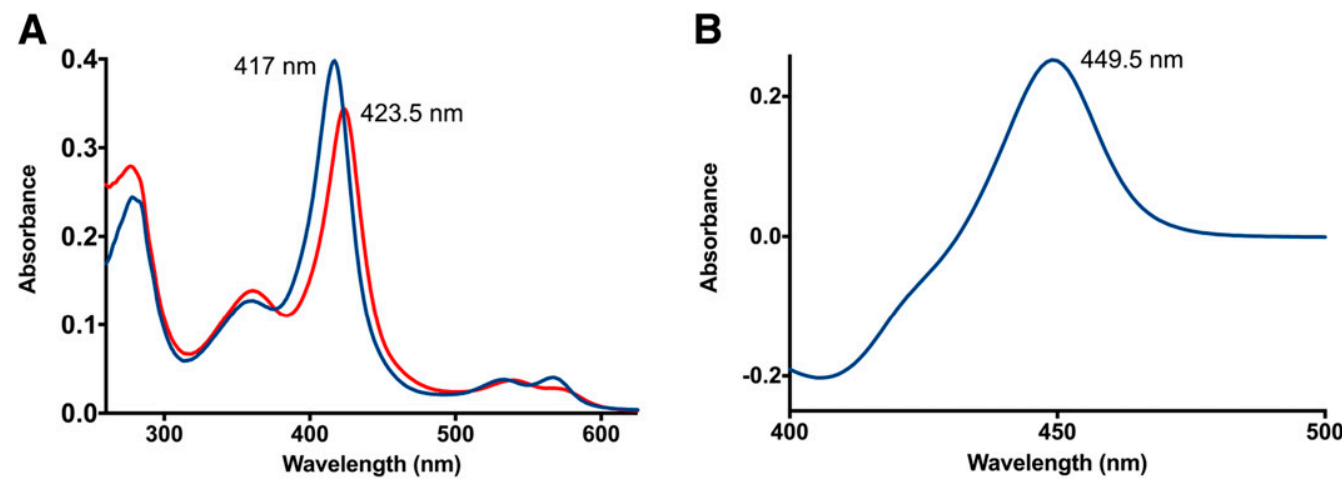

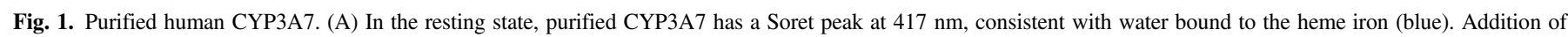

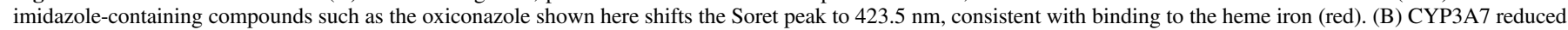
carbon-monoxide difference spectrum. 
TABLE 1

$\mathrm{IC}_{50}$ values and binding constants for CYP3A4 and CYP3A7

Values presented \pm S.E.

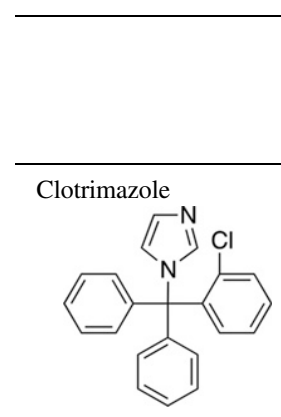

Liarozole

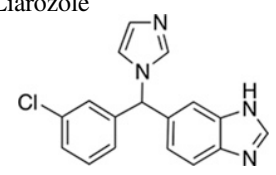

Ketoconazole

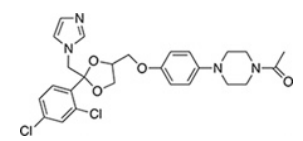

Oxiconazole<smiles>CCOC(C)=O</smiles>

Tioconazole<smiles>Clc1ccc(C(Cn2ccnc2)OCc2ccsc2Cl)c(Cl)c1</smiles>

Miconazole<smiles>Cc1ccc(COC(Cn2ccnc2)c2ccc(Cl)cc2Cl)c(Cl)c1</smiles>

Econazole<smiles>CCOC(C)=O</smiles>

$0.32 \pm 0.03$

$1.2 \pm 0.07$

$0.80 \pm 0.01$

$2.9 \pm 0.4^{* *}$

$1.0 \pm 0.06$

$4.9 \pm 0.7 * *$
Type II
$0.030 \pm 0.00$ $0.030 \pm 0.002$

Type II;
$0.032 \pm 0.005$

Type II; $0.84 \pm 0.1^{* *}$

Type II; $0.52 \pm 0.03 \quad 4.1 \pm 0.3^{* *}$

Type II; $0.69 \pm 0.05$

Type II; $11 \pm 0.4 * *$
Type II; $0.11 \pm 0.01$

$0.55 \pm 0.01 \quad 6.9 \pm 0.6^{* *}$

$3100 \pm 400$
$11,000 \pm 2000 *$
Type II;
Type II; $0.071 \pm 0.007$

Type II; $0.85 \pm 0.08 * *$ $1000 \pm 60$
Type II; $1700 \pm 80 * *$

Imidazole

¿ 
TABLE 1-Continued

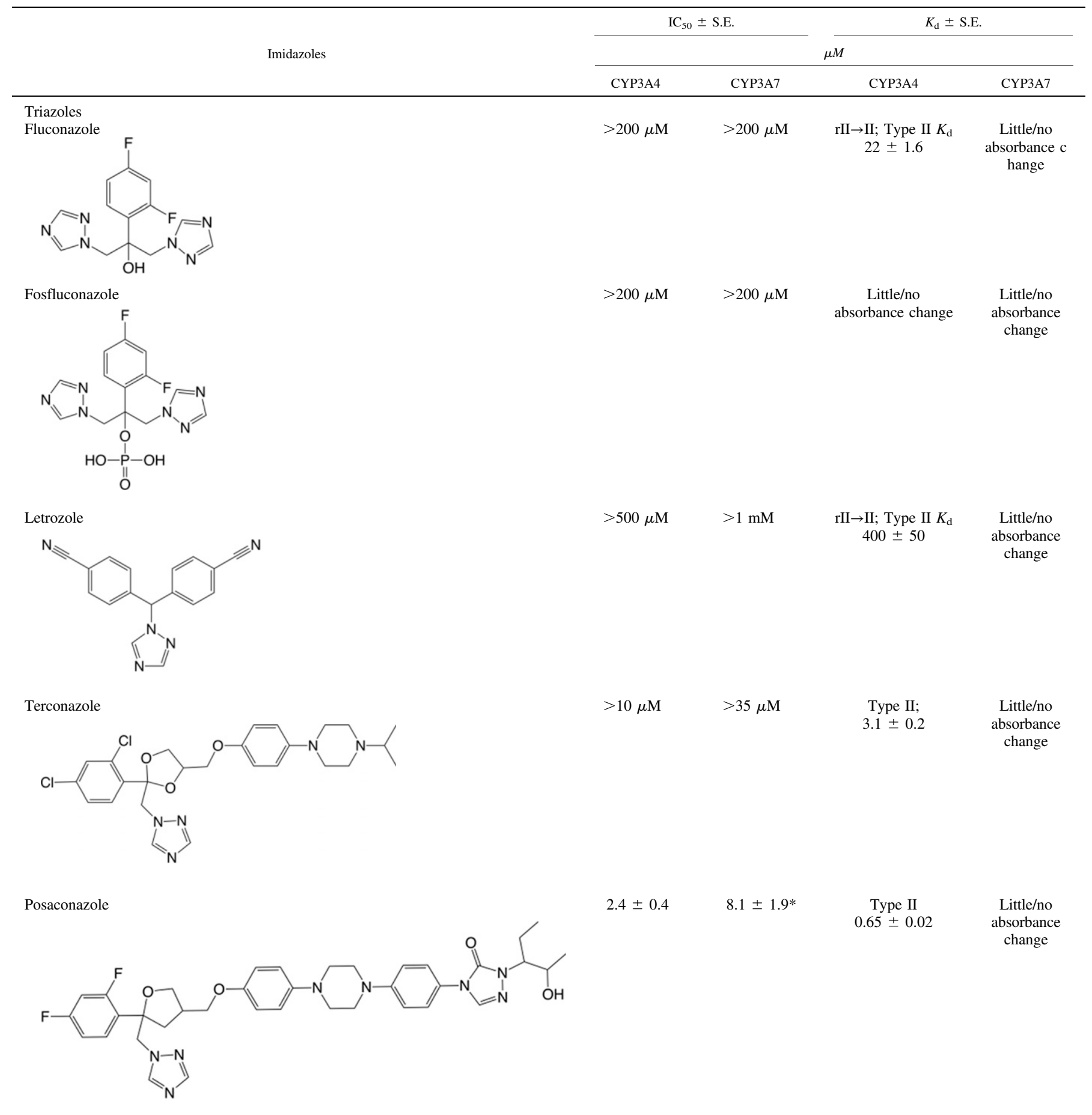

$* P<0.05 \%$

$* * P<0.01 \%$ compared with CYP3A4

expressed, highly purified CYP3A4 and CYP3A7 and a variety of substrates indicated that luciferin isopropyl alcohol was readily metabolized by both enzymes. Initial studies also established that under the reaction conditions used, initial velocities were linear up to 50 minutes, which is much longer than the 30 minutes used for subsequent experiments. Assays with both CYP3A7 and CYP3A4 over a range of substrate concentrations revealed Michaelis-Menten kinetics with a hyperbolic curve. CYP3A4 oxidized luciferin isopropyl alcohol more readily with a $K_{\mathrm{m}}$ value of $2.7 \mu \mathrm{M}$ and a $k_{\text {cat }}$ of 0.016 minute $^{-1}$. CYP3A7 performed the same reaction, albeit with a higher $K_{\mathrm{m}}$ of 11.6 $\mu \mathrm{M}$ and a lower $k_{\text {cat }}$ of 0.0009 minute $^{-1}$. Subsequent studies of CYP3A4 and CYP3A7 inhibition by azoles ( $\mathrm{IC}_{50}$ values) employed luciferin isopropyl alcohol as a substrate at concentrations equal to their respective $K_{\mathrm{m}}$ values. With the exception of imidazole, which was soluble in buffer, all other azoles were solubilized in DMSO. Thus, initial studies evaluated the impact of DMSO itself on CYP3A4 and 

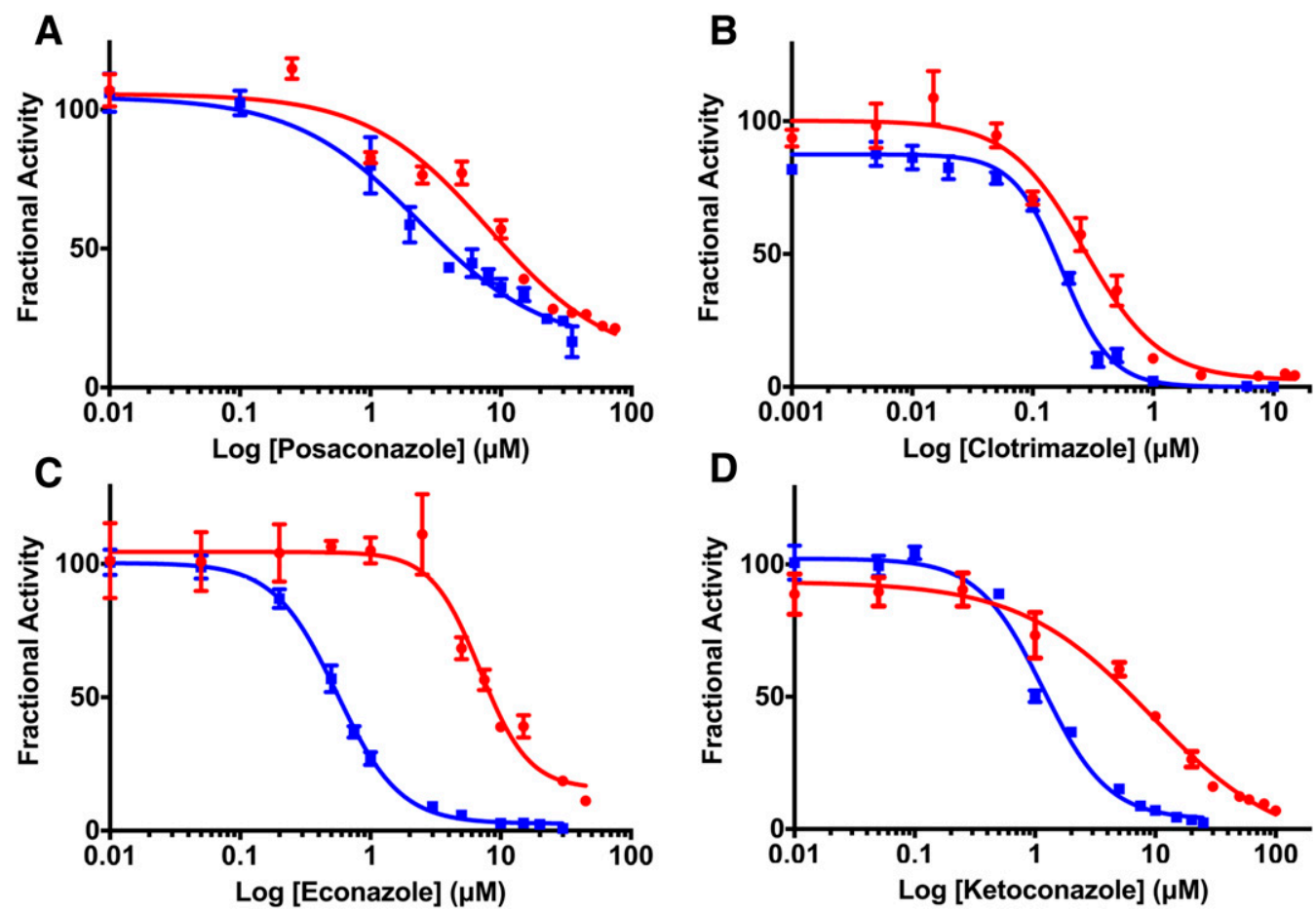

Fig. 2. Representative $\mathrm{IC}_{50}$ determinations and nonlinear regression fits for CYP3A4 (blue) and CYP3A7 (red). (A) Posaconazole is the only triazole demonstrating significant inhibition, with similar $\mathrm{IC}_{50}$ values for both enzymes. (B) Clotrimazole shows similarly high potency against both enzymes. (C) Econazole is 12.5 -fold more potent for CYP3A4 than for CYP3A7. (D) Ketoconazole is 7.7-fold more potent at inhibition of CYP3A4 than CYP3A7.

CYP3A7 inhibition. These assays determined that at $<0.3 \%(\mathrm{v} / \mathrm{v})$ and $<1 \%(\mathrm{v} / \mathrm{v})$ for CYP3A4 and CYP3A7, respectively, DMSO inhibition was $<25 \%$. As a result, all azole $\mathrm{IC}_{50}$ values determined herein maintained DMSO at these concentrations.

Of the 13 azoles examined, very different observations were made for those containing imidazole moieties versus those containing triazoles. Of the triazole-containing azoles, only posaconazole yielded significant inhibition, with $\mathrm{IC}_{50}$ values of $2-8 \mu \mathrm{M}$ for CYP3A4 and CYP3A7 (Fig. 2A). Each of the other triazoles studied were evaluated at higher and higher inhibitor concentrations, but the slight inhibition observed up to the limits shown in Table 1 for each compound is similar to that in controls containing DMSO solvent alone, omitting the azole. Thus, triazole-containing compounds exhibited little or no inhibition of either CYP3A enzyme, with the exception of posaconazole. The eight imidazole-containing inhibitor azoles all inhibited both enzymes, with varying potencies, but with consistently higher potency for CYP3A4 (Table 1). Clotrimazole was the most potent inhibitor of both enzymes and showed the least selectivity, 0.18 versus $0.27 \mu \mathrm{M}$ for CYP3A4 and CYP3A7, respectively (Fig. 2B). Other imidazole-containing compounds with submicromolar $\mathrm{IC}_{50}$ values for $\mathrm{CYP} 3 \mathrm{~A} 4$ included liarozole, econazole (Fig. 2C), and oxiconazole, with values for CYP3A7 being 5.9-, 12.5-, and 3.6-fold higher, respectively (Fig. 2C). Tioconazole, ketoconazole (Fig. 2D), and miconazole had $\mathrm{IC}_{50}$ values for CYP3A4 only slightly higher at $1-1.7 \mu \mathrm{M}$, with the corresponding values for CYP3A7 1.8- to 7.7-fold higher. Imidazole itself had a drastically reduced potency for both enzymes, with $\mathrm{IC}_{50}$ values in the millimolar range.

Azole Binding to CYP3A4 and CYP3A7. To further probe differences in interactions, these azoles were titrated into purified CYP3A4 and CYP3A7 while observing changes in UV-visible spectrum. Since each azole contains at least one nitrogen atom and the lone pair of this nitrogen is often capable of coordinating to the heme iron of cytochrome $\mathrm{P} 450$ proteins, a type II binding spectrum was expected for most compounds. Azoles with an imidazole moiety did indeed result in typical type II spectra, consisting of progressive decreases in absorbance at $410-412 \mathrm{~nm}$ and progressive increases in absorbance at 430-432 nm (Fig. 3). These imidazoles included clotrimazole, liarozole, ketoconazole, oxiconazole, tioconazole, miconazole, econazole, and imidazole itself. The binding affinity $\left(K_{\mathrm{d}}\right)$ for these imidazole compounds ranged from low nanomolar to millimolar values (Table 1). Imidazoles with the highest affinities and $K_{\mathrm{d}}$ values less than $70 \mathrm{nM}$ include clotrimazole binding to both enzymes and oxiconazole, tioconazole, and miconazole binding to CYP3A4. Compounds with affinities up to a $K_{\mathrm{d}}$ of $1 \mu \mathrm{M}$ included oxiconazole and miconazole binding to CYP3A7 and liarozole, ketoconazole, and econazole binding to CYP3A4. Imidazoles with yet lower affinity resulting from $K_{\mathrm{d}}$ values in the range of $1-11 \mu \mathrm{M}$ included tioconazole, econazole, liarozole, and ketoconazole binding to CYP3A7. Finally, significantly lower affinities were observed for imidazole itself, binding to each P450 enzyme ( $\geq 1000 \mu \mathrm{M})$.

In contrast, ligands with triazole moieties demonstrated varied interactions with CYP3A enzymes. While CYP3A4 titration with fosfluconazole did not elicit significant perturbation of the spin-state equilibrium, as evidenced by very little change in the difference spectra, the remaining triazole-containing compounds did. Terconazole and posaconazole (Fig. 4A) demonstrated clear type II shifts similar to the imidazole-containing compounds, while fluconazole and letrozole demonstrated more complex binding spectra. Both fluconazole and letrozole titrations started out with a clear increase in absorbance at 410 $414 \mathrm{~nm}$ and minima at $431-433 \mathrm{~nm}$, then switched to typical type II spectra at higher ligand concentrations (Fig. 4B). The early spectral changes with a peak at $\sim 410 \mathrm{~nm}$ and minimum at $\sim 432 \mathrm{~nm}$ are unusual but clearly represent a distinct binding mode. As the wavelengths are similar to those of a typical type II spectrum but with inverted peak and trough, according to historical precedent with type I and reverse type I spectra, we are calling this phenomenon a reverse type II spectra (rII). 
A

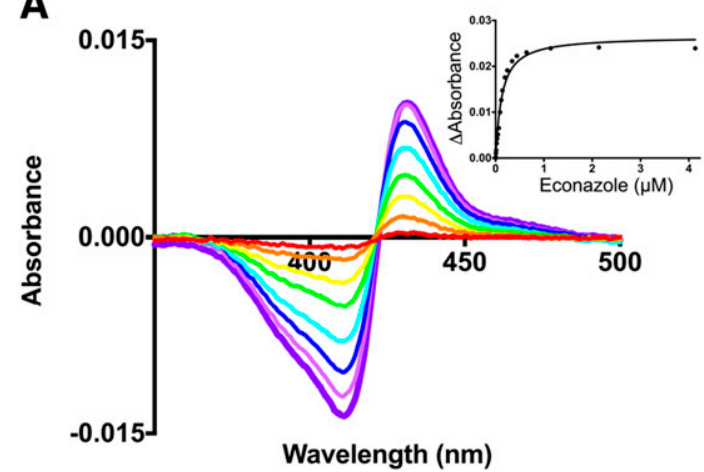

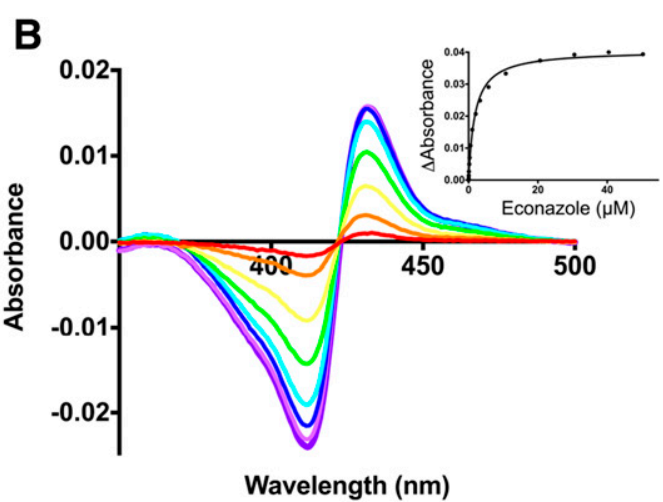

Fig. 3. Difference spectra for imidazole-containing azole binding to CYP3A enzymes demonstrate spectral shifts associated with type II binding. (A) Econazole binds very tightly to CYP3A4 (0.1 $\mu \mathrm{M}$ in a $5 \mathrm{~cm}$ cuvette) and was fit to the tight-binding equation (inset). (B) Econazole did not bind as tightly to CYP3A7 (1 $\mu \mathrm{M}$ in a $1 \mathrm{~cm}$ cuvette) and was fit to the standard equation (inset). Spectra obtained with increasing concentrations (rainbow order) of econazole are shown. Not all spectra are shown for clarity. All other ligands containing an imidazole moiety showed very similar type II spectral changes (data not shown).

In both cases the transition from one type of spectral shift to the second was accomplished with a clear isosbestic point. Overall these observations suggest that CYP3A4 may bind these triazoles in various modes that are spectrally distinguishable and, furthermore, that ligand positioning can be dependent on the ligand concentration. For all four triazoles demonstrating spectral shifts with CYP3A4, the data points associated with the type II shift could be fit to estimate the $K_{\mathrm{d}}$ values (Table 1). Posaconazole (Fig. 4A) and terconazole bound most tightly (0.65 and $3.1 \mu \mathrm{M}$, respectively), while fluconazole was an order of magnitude higher $(22 \mu \mathrm{M})$ and letrozole even higher (400 $\mu \mathrm{M}$; Fig. 4B). In contrast, the same series of triazole-containing compounds caused little or no spectral shift for CYP3A7, in all cases $<10 \%$ of that observed for CYP3A4 under the same conditions (Fig. 4, C and D). This result suggests that CYP3A7 either does not readily bind triazoles or at least does not do so in the same way observed for CYP3A4. Since fluconazole appears to bind CYP3A4 but not CYP3A7, this compound may be an interesting probe of the structural differences between the two enzymes.

\section{Discussion}

The human fetal CYP3A7 enzyme is the dominant drug-metabolizing enzyme in the earliest stage of life. In adults, CYP3A4 is expressed but typically not CYP3A7. However, detailed structure/function studies have been severely limited for CYP3A7, especially by comparison with
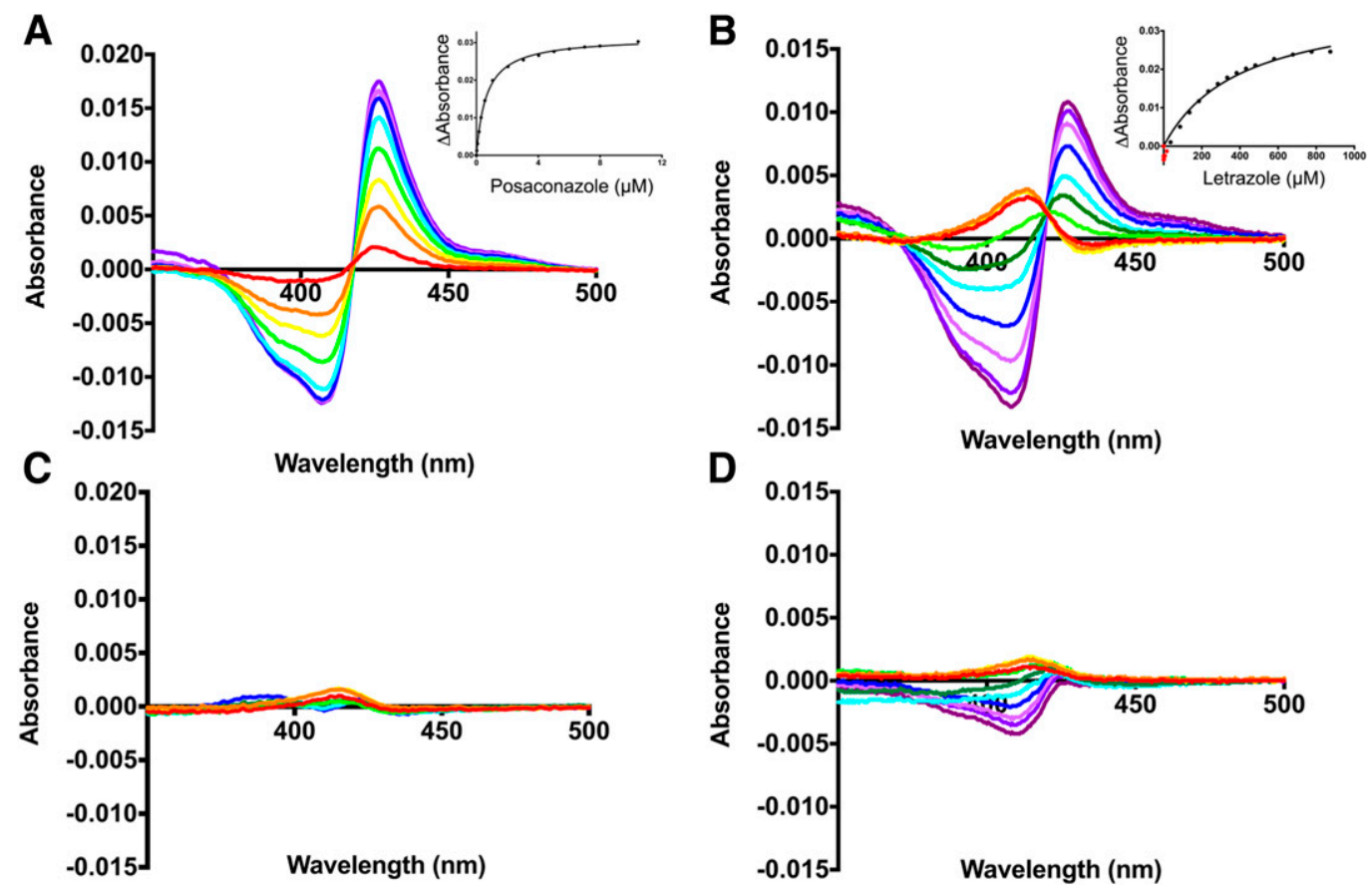

Fig. 4. Difference spectra for triazole-containing ligands binding to CYP3A enzymes demonstrate varied binding modes for CYP3A4 and little/no binding to CYP3A7. (A) Posaconazole binding to CYP3A4 $(1 \mu \mathrm{M})$ exhibits a typical type II shift. The associated $\Delta \mathrm{A}_{\max }$ vs. [ligand] data are fit to the standard equation (inset). (B) Letrozole binding to CYP3A4 $(1 \mu \mathrm{M})$ demonstrates two distinct binding modes, starting with a reverse type II and transitioning to a typical type II spectrum. While all points are shown in the inset, $\Delta \mathrm{A}_{\max }$ values corresponding to the reverse type II spectra (red) are excluded, and only those associated with the type II spectra (black) were fit to the standard equation to determine the type II $\mathrm{K}_{\mathrm{d}}$ (inset). (C) Posaconazole titration into CYP3A7 1 (micromolar) yields little or no evidence of binding. (D) Similarly, letrozole addition to CYP3A7 $(1 \mu \mathrm{M})$ results in little evidence of binding. CYP3A7 spectra in (C and D) were obtained under the same conditions as the CYP3A4 spectra in (A and D) are shown on the same scale to facilitate comparison. Spectra obtained with increasing concentrations of ligand are shown in rainbow order. Not all spectra are shown for clarity. 
CYP3A4, in part due to access to purified enzyme. Fetal hepatocytes are often difficult to obtain and the CYP3A7 yields are low. A previous study initially reported difficulties expressing the human fetal CYP3A7 in $E$. coli. While the apoprotein was generated, as detected by Western blot, no reduced-CO spectrum could be detected in membrane fractions (Inoue et al., 2000), which the authors suggested might result from a defect in heme incorporation and associated folding. They found that mutation of T485 in CYP3A7 to the proline found at this position in CYP3A4 and CYP3A5 and/or coexpression of GroEL rescued the defect to result in a reduced-CO difference spectrum and DHEA 16-hydroxylase activity (Inoue et al., 2000), but these studies were limited to microsomes. Baculovirus Supersomes expressing CYP3A7 are also commercially available (Corning, NY). However, none of these sources are suitable for detailed structure/function studies, in which higher yields and purified enzyme are needed. The construct and protocols described herein constitute a stable and high purity source of the primary fetal human drug-metabolizing enzyme. Like many other human P450 enzymes engineered for structure/function work, the wildtype sequence truncated at the $\mathrm{N}$-terminal end yields an enzyme that retains enzyme function in terms of ligand binding and catalytic activity. In this case, no T485P mutation was required, although the protein was coexpressed with GroEL/ES. The availability of significant quantities of highly purified, stable, recombinant CYP3A7 facilitated comparison with the similarly prepared major adult enzyme, CYP3A4.

As a class, the imidazole-containing drugs all appear to bind with the type II interaction expected for coordination of the imidazole to the heme iron. They are consistent and relatively potent inhibitors for both enzymes, with $\mathrm{IC}_{50}$ values from 0.18 to $9.2 \mu \mathrm{M}$. The huge difference in $\mathrm{IC}_{50}$ values and $K_{\mathrm{d}}$ values among imidazole itself and any of the imidazole-containing drugs underscores the importance of additional interactions with the protein. All of these drugs contain an sp3hybridized carbon alpha or beta to the imidazole ring, with two or three aromatic substituents of varying lengths. This overall shape should fit well with the CYP3A4 active site, which is generally more constricted near the iron where the imidazole ring would be and then tends to broaden out distally (Williams et al., 2004), with hydrophobic residues available to interact with aromatic portions of ligands. All of these drugs contain one or more chloro substituents, which would have the potential to form halogen bonds with the protein. Although the identity of imidazole drugs interacting with the two enzymes is the same, CYP3A7 has consistently higher $\mathrm{IC}_{50}$ values (1.5- to 12.5 -fold higher) and higher $K_{\mathrm{d}}$ values compared with CYP3A4. The only exception is clotrimazole where the difference between the $K_{\mathrm{d}}$ values is in the range of the error. Thus, this information suggests that, all other things being equal, the potential for adverse drug-drug interactions may actually be decreased for neonates on antifungals compared with adults.

The triazole-containing molecules have varied profiles. Fosfluconazole did not yield spectral evidence of binding at all and did not inhibit either enzyme. In contrast, fluconazole, letrozole, terconazole appeared to bind CYP3A4, as evidenced by a concentration-dependent shift of the spin-state equilibrium, but did so in such a way that they did not inhibit turnover. These same triazoles provided no evidence of binding to CYP3A7 and similarly did not inhibit metabolism. Posaconazole caused a spin-state shift only for CYP3A4 but inhibited both CYP3A enzymes. Clearly ligand binding, the first step in the catalytic cycle, is necessary but not sufficient for inhibition of CYP3A4. At least posaconazole can bind CYP3A7 without causing a significant spectral shift because it inhibits turnover. Similar to the imidazole observations, however, posaconazole inhibition of CYP3A7 was weaker than inhibition of CYP3A4. Finally, when triazoles did bind to CYP3A4, the $K_{\mathrm{d}}$ was much higher than most of the imidazole compounds, paralleling the trend in $\mathrm{IC}_{50}$ values for triazoles versus imidazoles.
Perhaps the most interesting aspect of the current study is the evidence of multiple binding modes in the spectral shifts for two of the triazoles with CYP3A4. At low concentrations of fluconazole and letrozole, the difference spectra demonstrate a clear atypical peak at $\sim 410-414 \mathrm{~nm}$ and a trough at $431-433 \mathrm{~nm}$. In terms of having the peak at shorter wavelengths and the trough at longer wavelengths, these spectra are similar to the typical type I spectral shift, indicative of water displacement from the heme iron (peak at $390 \mathrm{~nm}$ and trough at $430 \mathrm{~nm}$ ), but the peak is red-shifted by $\sim 20 \mathrm{~nm}$. In contrast, other established binding modes have the opposite phase, with a trough at shorter wavelengths and the peak at longer wavelengths. The reverse type I spectral shifts associated with ligand binding reinforcing water interaction with the heme iron typically have a trough at $\sim 390 \mathrm{~nm}$ and a peak at $\sim 422 \mathrm{~nm}$ (Ouellet et al., 2011). Electronic paramagnetic resonance studies have shown that 1,2,4-triazoles do not form water-bridged complexes in CYP3A4 (Lockart et al., 2018). Type II difference spectra associated with ligand nitrogen binding to the heme iron have a trough at $\sim 410 \mathrm{~nm}$ and a peak at $\sim 434$. Thus, the wavelengths most closely match those of the type II interaction, but the relationship of peak to trough most resembles that of type I. Thus, according to historical precedent, the current observations will be referred to as a reverse type II (rII) spectral shift. For both ligands, this reverse type II spectral shift is present most strongly at the beginning of the titration and then progressively morphs into a canonical type II spectral shift at high ligand concentrations. The spectral progression and sharp isosbestic point clearly suggests a transition from one binding mode at low concentrations to a typical type II binding mode at high ligand concentrations. Letrozole, one of the triazoles demonstrating this transition, is known to be oxidized by CYP3A4 to form a carbinol product from which the triazole has been cleaved (Murai et al., 2009). The initial binding mode could be consistent with an orientation suitable for metabolism, whereas reorientation at higher ligand concentrations would be consistent with inhibition. Regardless of the orientations involved, the fact that the observations depend on ligand concentration suggests that a second copy of the ligand may bind. This has been observed for a structure of CYP3A4 with ketoconazole, where one copy coordinates the heme iron via its imidazole and the second copy binds in an antiparallel fashion more distal from the heme. However, as seen herein, the binding curve for ketoconazole represents a single phase for the type II shift. Thus, spectral binding experiments may report only on binding of the ligand copy interacting most closely interacting with the heme. In contrast, for some ligands like fluconazole and letrozole, binding of a second ligand molecule may alter the orientation of the first ligand molecule, as would be consistent with their binding spectra. While other interpretations cannot be excluded, overall these observations indicate that CYP3A4 binds some triazoles in more than one orientation and the orientation can be dependent on the ligand concentration.

In summary, CYP3A4 and CYP3A7 appear to be inhibited by the same range of azole compounds. The CYP3A4 active site is known to be very flexible, depending on adapting to the scaffold of different bound ligands, so the similarity of the inhibition profiles suggests that CYP3A7 is likely generally to retain this feature. However, inhibition of CYP3A7 was consistently weaker than inhibition of CYP3A4, which may provide some additional leeway in dosing safety margins in infants. Along these lines, it appears that the likelihood of possible drug-drug interactions would be higher for imidazole-containing compounds versus triazolecontaining compounds as the latter inhibit either not at all or more weakly. Finally, transitions between multiple binding modes were identified, suggesting additional complexity in CYP3A4 interactions with some triazoles. 


\section{Acknowledgments}

We thank Jed Lampe for urging us to work on CYP3A7 and for suggesting some of the azoles used in this study.

\section{Authorship Contributions}

Participated in research design: Godamudunage, Scott.

Conducted experiments: Godamudunage, Grech.

Performed data analysis: Godamudunage.

Wrote or contributed to the writing of the manuscript: Godamudunage, Scott.

\section{References}

Bart AG and Scott EE (2017) Structural and functional effects of cytochrome $b_{5}$ interactions with human cytochrome P450 enzymes. J Biol Chem 292:20818-20833.

Blake MJ, Castro L, Leeder JS, and Kearns GL (2005) Ontogeny of drug metabolizing enzymes in the neonate. Semin Fetal Neonatal Med 10:123-138.

Canadian Paediatric Society (2008) Antifungal agents for common paediatric infections. Can J Infect Dis Med Microbiol 19:15-18.

DeVore NM, Smith BD, Wang JL, Lushington GH, and Scott EE (2009) Key residues controlling binding of diverse ligands to human cytochrome P450 2A enzymes. Drug Metab Dispos 37: 1319-1327.

Ekroos M and Sjögren T (2006) Structural basis for ligand promiscuity in cytochrome P450 3A4. Proc Natl Acad Sci USA 103:13682-13687.

Fonvielle M, Le Du MH, Lequin O, Lecoq A, Jacquet M, Thai R, Dubois S, Grach G, Gondry M, and Belin P (2013) Substrate and reaction specificity of Mycobacterium tuberculosis cytochrome P450 CYP121: insights from biochemical studies and crystal structures. $J$ Biol Chem 288: $17347-17359$.

Granfors MT, Wang JS, Kajosaari LI, Laitila J, Neuvonen PJ, and Backman JT (2006) Differential inhibition of cytochrome P450 3A4, 3A5 and 3A7 by five human immunodeficiency virus (HIV) protease inhibitors in vitro. Basic Clin Pharmacol Toxicol 98:79-85.

Gupta AK, Cooper EA, Ryder JE, Nicol KA, Chow M, and Chaudhry MM (2004) Optimal management of fungal infections of the skin, hair, and nails. Am J Clin Dermatol 5:225-237.

Hsieh EM, Hornik CP, Clark RH, Laughon MM, Benjamin DK Jr., and Smith PB; Best Pharmaceuticals for Children Act—Pediatric Trials Network (2014) Medication use in the neonatal intensive care unit. Am J Perinatol 31:811-821.

Hsu MH, Savas U, and Johnson EF (2018) The X-ray crystal structure of the human monooxygenase cytochrome P450 3A5-ritonavir complex reveals active site differences between P450s 3A4 and 3A5. Mol Pharmacol 93:14-24.

Inoue E, Takahashi Y, Imai Y, and Kamataki T (2000) Development of bacterial expression system with high yield of CYP3A7, a human fetus-specific form of cytochrome P450. Biochem Biophys Res Commun 269:623-627.

Kaufman DA, Morris A, Gurka MJ, Kapik B, and Hetherington S (2014) Fluconazole prophylaxis in preterm infants: a multicenter case-controlled analysis of efficacy and safety. Early Hum Dev 90 (Suppl 1):S87-S90.

Kumar P, Walker JK, Hurt KM, Bennett KM, Grosshans N, and Fotis MA (2008) Medication use in the neonatal intensive care unit: current patterns and off-label use of parenteral medications. J Pediatr 152:412-415.

Lass-Flörl C (2010) Invasive fungal infections in pediatric patients: a review focusing on antifungal therapy. Expert Rev Anti Infect Ther 8:127-135.

Leeder JS, Gaedigk R, Marcucci KA, Gaedigk A, Vyhlidal CA, Schindel BP, and Pearce RE (2005) Variability of CYP3A7 expression in human fetal liver. J Pharmacol Exp Ther 314: 626-635.

Lockart MM, Rodriguez CA, Atkins WM, and Bowman MK (2018) CW EPR parameters reveal cytochrome P450 ligand binding modes. J Inorg Biochem 183:157-164.

Lucker GP, Heremans AM, Boegheim PJ, van de Kerkhof PC, and Steijlen PM (1997) Oral treatment of ichthyosis by the cytochrome P-450 inhibitor liarozole. Br J Dermatol 136:71-75.

Mast N, Charvet C, Pikuleva IA, and Stout CD (2010) Structural basis of drug binding to CYP46A1, an enzyme that controls cholesterol turnover in the brain. J Biol Chem 285: 31783-31795.
Mast N, Zheng W, Stout CD, and Pikuleva IA (2013) Antifungal azoles: structural insights into undesired tight binding to cholesterol-metabolizing CYP46A1. Mol Pharmacol 84:86-94.

Murai K, Yamazaki H, Nakagawa K, Kawai R, and Kamataki T (2009) Deactivation of anti-cancer drug letrozole to a carbinol metabolite by polymorphic cytochrome P450 2A6 in human liver microsomes. Xenobiotica 39:795-802.

Omura T and Sato R (1962) A new cytochrome in liver microsomes. J Biol Chem 237:1375-1376.

Ouellet H, Kells PM, Ortiz de Montellano PR, and Podust LM (2011) Reverse type I inhibitor of Mycobacterium tuberculosis CYP125A1. Bioorg Med Chem Lett 21:332-337.

Poulos TL and Howard AJ (1987) Crystal structures of metyrapone- and phenylimidazole-inhibited complexes of cytochrome P-450cam. Biochemistry 26:8165-8174.

Regan MM, Neven P, Giobbie-Hurder A, Goldhirsch A, Ejlertsen B, Mauriac L, Forbes JF, Smith I, Láng I, Wardley A, et al.; BIG 1-98 Collaborative Group; International Breast Cancer Study Group (IBCSG) (2011) Assessment of letrozole and tamoxifen alone and in sequence for postmenopausal women with steroid hormone receptor-positive breast cancer: the BIG 1-98 randomised clinical trial at 8.1 years median follow-up. Lancet Oncol 12:1101-1108.

Sevrioukova IF and Poulos TL (2017) Structural basis for regiospecific midazolam oxidation by human cytochrome P450 3A4. Proc Natl Acad Sci USA 114:486-491.

Seward HE, Roujeinikova A, McLean KJ, Munro AW, and Leys D (2006) Crystal structure of the Mycobacterium tuberculosis P450 CYP121-fluconazole complex reveals new azole drug-P450 binding mode. J Biol Chem 281:39437-39443.

Shen AL, Porter TD, Wilson TE, and Kasper CB (1989) Structural analysis of the FMN binding domain of NADPH-cytochrome P-450 oxidoreductase by site-directed mutagenesis. J Biol Chem 264:7584-7589.

Stevens JC (2006) New perspectives on the impact of cytochrome P450 3A expression for pediatric pharmacology. Drug Discov Today 11:440-445.

Stevens JC, Hines RN, Gu C, Koukouritaki SB, Manro JR, Tandler PJ, and Zaya MJ (2003) Developmental expression of the major human hepatic CYP3A enzymes. J Pharmacol Exp Ther 307:573-582.

Strushkevich N, Usanov SA, and Park HW (2010) Structural basis of human CYP51 inhibition by antifungal azoles. J Mol Biol 397:1067-1078.

Tang C, Chiba M, Nishime J, Hochman JH, Chen I, Williams TM, and Lin JH (2000) Comparison of imidazole- and 2-methyl imidazole-containing farnesyl-protein transferase inhibitors: in teraction with and metabolism by rat hepatic cytochrome P450s. Drug Metab Dispos 28: $680-686$.

Tréluyer JM, Bowers G, Cazali N, Sonnier M, Rey E, Pons G, and Cresteil T (2003) Oxidative metabolism of amprenavir in the human liver. Effect of the CYP3A maturation. Drug Metab Dispos 31:275-281.

Vahlquist A, Blockhuys S, Steijlen P, van Rossem K, Didona B, Blanco D, and Traupe H (2014) Oral liarozole in the treatment of patients with moderate/severe lamellar ichthyosis: results of a randomized, double-blind, multinational, placebo-controlled phase II/III trial. Br J Dermatol 170: $173-181$.

Wilkinson CF, Hetnarski K, Cantwell GP, and Di Carlo FJ (1974) Structure-activity relationships in the effects of 1-alkylimidazoles on microsomal oxidation in vitro and in vivo. Biochem Pharmacol 23:2377-2386.

Williams JA, Ring BJ, Cantrell VE, Jones DR, Eckstein J, Ruterbories K, Hamman MA, Hall SD, and Wrighton SA (2002) Comparative metabolic capabilities of CYP3A4, CYP3A5, and CYP3A7. Drug Metab Dispos 30:883-891.

Williams PA, Cosme J, Vinkovic DM, Ward A, Angove HC, Day PJ, Vonrhein C, Tickle IJ, and Jhoti $\mathrm{H}$ (2004) Crystal structures of human cytochrome P450 3A4 bound to metyrapone and progesterone. Science 305:683-686.

Yano JK, Wester MR, Schoch GA, Griffin KJ, Stout CD, and Johnson EF (2004) The structure of human microsomal cytochrome P450 3A4 determined by X-ray crystallography to 2.05-A resolution. J Biol Chem 279:38091-38094.

Zanger UM and Schwab M (2013) Cytochrome P450 enzymes in drug metabolism: regulation of gene expression, enzyme activities, and impact of genetic variation. Pharmacol Ther 138: $103-141$.

Address correspondence to: Emily E. Scott, Department of Medicinal Chemistry, University of Michigan, 428 Church St., Ann Arbor, MI 48109. E-mail: scottee@ umich.edu 